\title{
Screening of ligninolytic fungi for bioremediation of dyes
}

\author{
Seri Amelie Muliyadi, Elida Tengku Zainal Mulok, Noor Hana Hussein, Rohana Mat Nor* \\ School of Biology, Faculty of Applied Sciences, Universiti Teknologi MARA, 40450 Shah Alam, Selangor, Malaysia
}

Received 27th November 2020 / Accepted 29th March 2021

\begin{abstract}
Water pollution is a growing concern worldwide. One of the main causes of water pollution includes the textile industry which produces a large amount of wastewater every day. This wastewater is known to contain dyes that are recalcitrant and hard to treat. In order to solve this problem, bioremediation using ligninolytic fungi is commonly used for the ligninolytic enzymes which are able to break down the dyes. In this study, samples were collected from decaying woods and soils in the vicinity of UiTM Puncak Alam forests. A total of 20 fungal isolates were tested for ligninolytic enzyme production. Out of the 20 isolates, 13 were found to produce lignin peroxidase and manganese peroxidase, but only one produced laccase. The isolate that produced all three enzymes was used for DNA isolation and identified using amplification of the ITS region by PCR. The isolate was identified as Trichoderma asperellum, a soft rot fungal species which is renowned for its role in bioremediation as a biosorbent.
\end{abstract}

Keywords: Bioremediation, laccase, ligninolytic fungi, peroxidases, Trichoderma spp.

\section{INTRODUCTION}

Water, despite being crucial for sustaining life, is frequently polluted nowadays and is rendered harmful. In fact, the impairment of water is regarded as the leading cause of death and diseases worldwide (Pink, 2006). Among the main causes of water pollution is the textile industry, which is one of the most chemically intensive industries on Earth (Kant, 2012).

Wastewater from the textile industry contains a large amount of dyes due to the incomplete exhaustion of dyes onto the fibres of fabrics (Pearce et al., 2003). These dyes are highly stable to a lot of factors and persist in the environment. They are considered to be the most difficult constituent to treat in the textile wastewater and may even escape conventional wastewater treatment methods (Couto, 2009; Doble \& Kumar, 2005).

The existing textile wastewater treatment methods have various problems, such as high operation and maintenance costs, the requirement of specialised equipment, the use of high energy levels and the introduction of secondary contaminants and sludge (Adegoke \& Bello, 2015; dos Santos et al., 2007; Katheresan et al., 2018). Hence, bioremediation is an attractive alternative to solve the problems.

Bioremediation is the utilisation of living things to treat pollutants by adsorption or breaking down of the pollutants into less toxic substances. It is usually preferred due to its low cost, efficiency and compatibility with the environment (Ali et al., 2009). In bioremediation, wood rot fungi are commonly used due to their robustness and their enzymes. There are three types of wood rot fungi, the white rot, brown rot, and soft rot fungi. Among the three fungi, the white rot fungi are the most commonly studied in bioremediation, mainly due to their high levels of ligninolytic enzymes.

*Author for correspondence: Rohana Mat Nor, School of Biology, Faculty of Applied Sciences, Universiti Teknologi MARA, 40450 Shah Alam, Selangor, Malaysia. Email - rohana_micro@salam.uitm.edu.my 
Ligninolytic enzymes, such as laccase, lignin peroxidase and manganese peroxidase, break down lignin to carbohydrates that are easier to metabolize, namely hemicellulose and cellulose (Leonowicz et al., 1999; Mir-Tutusaus et al., 2018). They are used in the biodegradation of dyes as they are non-specific due to their action by generation of radicals (Mir-Tutusaus et al., 2018). Some dyes also have structural similarity to lignin structures, hence increasing the susceptibility towards the enzymes (Wesenberg et al., 2003). Therefore, there is an attractiveness to study fungi that are able to produce ligninolytic enzymes to be used in the bioremediation of dyes.

In this study, fungi were isolated from the forests of Universiti Teknologi MARA Puncak Alam, Selangor, Malaysia (N 3¹1'58.501', E $\left.101^{\circ} 26^{\prime} 44.54^{\prime \prime}\right)$. Their capabilities to produce ligninolytic enzymes were tested using enzymatic assays for laccase, lignin peroxidase and manganese peroxidase. The isolates which tested positive for both assays were then identified using gene sequencing of the internal transcribed spaced (ITS) region.

\section{MATERIALS AND METHODS}

\section{Microorganisms}

Culture plates containing mycelia of Pleurotus pulmonarius was purchased from the Forest Research Institute Malaysia (FRIM) and acts as the positive control for the enzymatic assays as it is a well-studied ligninolytic fungus capable of producing the target ligninolytic enzymes in order to decolourise dyes, as shown in the studies by Tychanowicz et al. (2004), dos Santos Bazanella et al. (2013), da Silva et al. (2016) and Lallawmsanga et al. (2019).

\section{Sample collection}

A total of 20 fungal samples were collected from decaying woods on trees and the soil-around them in the vicinity of the forests of UiTM Puncak Alam (N 3011'58.501', E 101²6'44.54'). The samples were chosen based on the decay produced onto the trees, which may indicate the presence of fungal ligninolytic enzymes. The fungal bodies were scraped off the decaying woods using a knife. When collecting soil samples, only the surface litter was collected along with the fungal bodies. During transportation, the samples were kept in sterile resealable bags in the dark at room temperature. Prior to cultivation, the samples were washed with $70 \%(\mathrm{v} / \mathrm{v})$ ethanol to eliminate surface contaminants. The samples were inoculated on potato dextrose agar (PDA) containing chloramphenicol to inhibit the growth of bacteria at $28^{\circ} \mathrm{C}$ for five days. The isolates were purified through repeated subculturing and grown at $28^{\circ} \mathrm{C}$ for five days each time. The pure isolates were then maintained in $50 \%(\mathrm{v} / \mathrm{v})$ glycerol stock solutions at $-70^{\circ} \mathrm{C}$ for long time storage (Paul et al., 2015; Yuan et al., 2012).

\section{Enzymatic assays}

The lignin peroxidase and manganese peroxidase assay was based on Pointing (1999). The culture of $P$. pulmonarius was used as the positive control. The isolates were first cultivated in lignin modifying enzyme basal media (LBM) supplemented with $0.4 \%(\mathrm{w} / \mathrm{v})$ glucose and $1.6 \%$ (w/v) agar at $28^{\circ} \mathrm{C}$ for 24 hours in order to acclimate the fungi to the agar. A new LBM media supplemented with $0.01 \%(\mathrm{w} / \mathrm{v})$ Azure B and $1.6 \%(\mathrm{w} / \mathrm{v})$ agar was prepared prior to autoclaving at $121^{\circ} \mathrm{C}$ at $100 \mathrm{kPa}$ for 15 minutes. An amount of $1 \mathrm{ml}$ of sterilized $20 \%$ (w/v) aqueous glucose was added per $100 \mathrm{ml}$ of the media prepared. The media was then poured into Petri dishes before being inoculated with fungal isolates. The negative control plate was without the fungal isolates. The plates were later incubated at $25^{\circ} \mathrm{C}$ and examined daily for 10 days. The presence of the enzymes was indicated by the clearance of the blue coloured medium.

The method for laccase detection was adapted from Johannes and Majcherczyk (2000). The culture of $P$. pulmonarius was used as the positive control, while the negative control was distilled water. The isolates were grown in potato dextrose broth (PDB) for five days prior to being filtered. A total of $100 \mu \mathrm{L}$ of cell supernatant was added to $0.5 \mathrm{mM} \mathrm{2,2'-azino-bis(3-ethylbenzothiazoline-6-}$ sulphonic acid) (ABTS) and $0.1 \mathrm{M}$ sodium acetate buffer. The presence of laccase enzymes was indicated by the presence of green colouration in the mixture. Laccase is known to be able to oxidise ABTS into ABTS-azine, a green and soluble end-product (Niku-Paavola et al., 1990), as shown in Equation (1). 


\section{ABTS
(colourless, insoluble $)$$\stackrel{\text { +laccase }}{\longrightarrow} \begin{gathered}\text { ABTS-azine } \\ \text { (green, soluble) }\end{gathered}$}

\section{Macroscopic and microscopic characterisation}

The fungal isolates were grown on PDA for five days at $28^{\circ} \mathrm{C}$ prior to being observed using the adhesive tape method. In this method, transparent cellophane tape was placed on top of the cultures, and then transferred to glass slides with a drop of methylene blue before being observed using the light microscope (Olympus CX21, Japan) under a total magnification of 400x.

\section{DNA extraction}

The DNA extraction method was adapted from Chi, Park and Lee (2008) with a slight modification. Instead of growing the fungal isolates on agar as suggested by the method, the fungal isolates were grown in PDB on a $120 \mathrm{rpm}$ shaker for 5 days to increase the DNA yield. This is because more cells can be harvested through a submerged culture. Agitating the cultures promotes better heat and mass transfer (Tang et al., 2006). This, in turn, helps with the aeration of the cultures, and as pointed out by AgudeloEscobar and his colleagues in 2017, high agitation and high aeration favour biomass production. The fungal cultures were filtered and ground with liquid nitrogen before addition of $0.5 \mathrm{ml}$ extraction buffer $(1 \mathrm{M} \mathrm{KCl}, 100 \mathrm{mM}$ Tris- $\mathrm{HCl}$, and $10 \mathrm{mM}$ EDTA) in a sterile Eppendorf tube. The cell lysates were then centrifuged at $5000 \mathrm{rpm}$ for 10 minutes. The supernatant was then decanted into Eppendorf tubes containing $0.3 \mathrm{ml} \mathrm{2-}$ propanol. The remaining lysates and cell debris were discarded after decantation. The lysate and 2-propanol were mixed by inverting the tube prior to centrifugation at $12000 \mathrm{rpm}$ for 10 minutes. The supernatant was discarded, and the tube was washed with $0.8 \mathrm{ml} \mathrm{70 \%} \mathrm{(v/v)} \mathrm{ethanol.} \mathrm{Any}$ remaining ethanol was evaporated by drying at $37^{\circ} \mathrm{C}$ for 15 minutes. The DNA pellet was then dissolved by adding $50 \mu \mathrm{l}$ sterile distilled water and vortexed at a low speed. The DNA samples were stored at $-20^{\circ} \mathrm{C}$ until further use.

\section{Amplification of the ITS region}

Universal primers ITS1 (5'-
TCCGTAGGTGAACCTGCGG-3') and ITS4
(5'- TCTCCGCTTATTGATATGC-3') were synthesized in Malaysia by NextGene Sdn. Bhd. PCR was performed in a $50 \mu \mathrm{l}$ mixture containing $25 \mu \mathrm{l}$ EconoTaq PLUS GREEN 2X Master Mix, $1 \mu \mathrm{M}$ of each primer, $1 \mu \mathrm{l}$ of DNA template and $23 \mu \mathrm{l}$ sterile distilled water. The initial denaturation was carried out at $94^{\circ} \mathrm{C}$ for 2 minutes, followed by 35 cycles of denaturation at $94^{\circ} \mathrm{C}$ for 30 seconds, annealing at $55^{\circ} \mathrm{C}$ for 30 seconds and extension at $72^{\circ} \mathrm{C}$ for 1 minute, and finally the final extension at $72^{\circ} \mathrm{C}$ for 5 minutes. Sterile distilled water was used instead of the DNA template serving as the negative control. The PCR products were visualised using gel electrophoresis using 1\% (w/v) agarose gel stained with Gel Red at 80V for 1 hour and 30 minutes, then viewed using Omega Fluor ${ }^{\mathrm{TM}}$ (Aplegen ${ }^{\circledR}$, USA) prior to being sent for sequencing at MyTACG Biosciences, Malaysia. The resulting sequences were analysed using CHROMAS LITE software and aligned with the sequences in the NCBI database by using BLAST.

\section{RESULTS AND DISCUSSION}

\section{Sample Collection}

A total of 20 samples were collected from decaying woods on trees and the vicinity of the forests of UiTM Puncak Alam. The samples were mainly collected from decayed tree barks as the ligninolytic fungi would cause the barks to rot. All of the 20 samples were able to grow on PDA with chloramphenicol by direct plating and were isolated by repeated subculturing, whereby plugs of inoculated fungi were transferred onto new media after growing until pure fungal cultures were obtained.

\section{Screening for lignin peroxidase and manganese peroxidase production}

The screening for the production of lignin peroxidase and manganese peroxidase by the fungal isolates was based on the decolourisation of Azure B, as described by Pointing (1999). Prior to incubation with Azure B, the isolates were first incubated onto LBM agar. This was done to acclimate the fungal isolates to the media as well as reduce any carry over of nutrients that may influence the interpretation of the assay results 
(Pointing, 1999). Table 1 shows the results of the assay.

Out of the 20 isolates, only 13 isolates managed to exhibit a zone of clearance on the LBM agar with Azure B, hence only 13 isolates were positive for lignin peroxidase and manganese peroxidase production. The fungal isolates that did not decolourise the Azure B might be a false negative, as it may have lost the ability to produce the enzyme during repeated subculturing. Excessive subculturing during isolation may have affected the conidial yield, which in turn affected the extracellular enzyme production (Ansari \& Butt, 2011; Safavi, 2011).

Table 1. Lignin peroxidase and manganese peroxidase assays on isolates S1-S20.

\begin{tabular}{|c|c|c|}
\hline Sample & $\begin{array}{l}\text { Emergence of Zone of } \\
\text { Clearance }\end{array}$ & Interpretation of Result \\
\hline S1 & No & - \\
\hline S2 & Yes & + \\
\hline S3 & No & - \\
\hline S4 & Yes & + \\
\hline S5 & Yes & + \\
\hline S6 & Yes & + \\
\hline S7 & Yes & + \\
\hline S8 & No & - \\
\hline S9 & No & - \\
\hline S10 & Yes & + \\
\hline S11 & Yes & + \\
\hline S12 & No & - \\
\hline S13 & No & - \\
\hline S14 & Yes & + \\
\hline S15 & Yes & + \\
\hline S16 & No & - \\
\hline S17 & Yes & + \\
\hline S18 & Yes & + \\
\hline S19 & Yes & + \\
\hline S20 & Yes & + \\
\hline P. pulmonarius (Positive control) & Yes & + \\
\hline LBM + Antibiotic (Negative control) & No & - \\
\hline
\end{tabular}

$(+)$ : Presence of lignin peroxidase and manganese peroxidase; (-): Absence of lignin peroxidase and manganese peroxidase

\section{Detection of laccase production}

Laccase production can be interpreted by the oxidation of ABTS into ABTS-azine, a green and soluble substance. The result of the assay is shown in Table 2.

Out of the 20 isolates, only one isolate, S15, was able to oxidise ABTS into green coloured ABTS-azine, indicating the production of laccase. The high number of isolates which were tested negative for laccase production may have been unable to produce laccase or may have been false negatives due to the loss of ability to produce the enzyme. This is because the production of laccase can be affected by the stage of reproduction cycle it was in during collection (Wood, 1980). An example of this case was evidenced in Wood's study, whereby Agaricus bisporus was able to produce large amounts of laccase but rapidly lost its ability to produce the enzyme due to enzyme 
inhibition and enzyme degradation when forming fruiting bodies.

Hence, out of the 20 isolates, only one isolate, S15, was found to be positive for all three enzymes production. Thus, the isolate S15 was used for further investigation in this study.

Table 2. Laccase assay analysis on isolates S1-S20.

\begin{tabular}{|c|c|c|}
\hline Isolate & $\begin{array}{c}\text { Green } \\
\text { Colour } \\
\text { Formation }\end{array}$ & Laccase \\
\hline S1 & $\mathrm{No}$ & - \\
\hline $\mathrm{S} 2$ & $\mathrm{No}$ & - \\
\hline S3 & No & - \\
\hline S4 & No & - \\
\hline $\mathrm{S} 5$ & No & - \\
\hline S6 & No & - \\
\hline $\mathrm{S} 7$ & No & - \\
\hline S8 & No & - \\
\hline S9 & No & - \\
\hline S10 & No & - \\
\hline S11 & No & - \\
\hline S12 & No & - \\
\hline S13 & No & - \\
\hline S14 & No & - \\
\hline S15 & Yes & + \\
\hline S16 & No & - \\
\hline S17 & No & - \\
\hline S18 & No & - \\
\hline S19 & No & - \\
\hline S20 & No & - \\
\hline $\begin{array}{c}\text { P. pulmonarius } \\
\text { (Positive Control) }\end{array}$ & Yes & + \\
\hline $\begin{array}{l}\text { Sterile distilled water } \\
\text { (Negative control) }\end{array}$ & No & - \\
\hline
\end{tabular}

(+): Present; (-): Absent

\section{Macroscopic and characterisation}

When growing on PDA, isolate S15 exhibited fast growth. After four days, green pigments started being released, turning the background green while the mycelia of the fungi remained white, as shown in Figure 1.

Both isolate S15 and P. pulmonarius were observed under a light microscope with a total magnification of $400 \mathrm{x}$ using the cellophane technique. The results are shown in Table 3, with additional comparison to the T. asperellum isolate of Podder and Ghosh (2019). Isolate S15 appeared to show no resemblance at all to white rot fungi due to the absence of clamp connections, indicating that it is not a basidiomycete. The isolate instead shared similar characteristics with soft rot fungi such as the presence of septated hyphae and conidiophores. Conidia can also be observed around the hyphae.

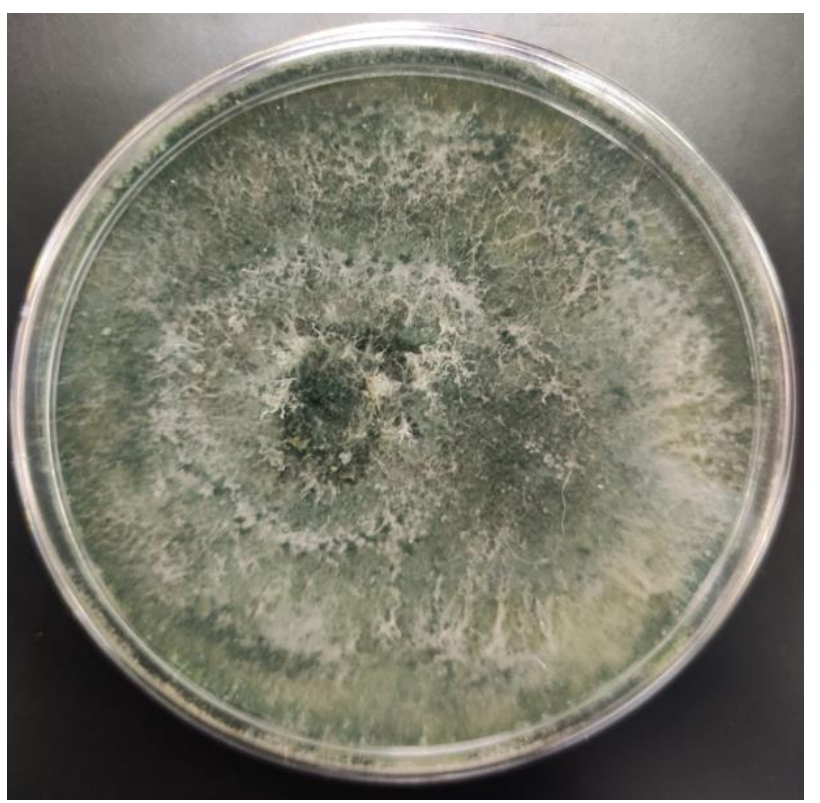

Figure 1. Isolate S15 grown on potato dextrose agar.

\section{Amplification of the ITS Region}

The amplification of the ITS region was done in order to identify the unknown isolate S15. Figure 2 shows the gel electrophoresis results for the amplification of the ITS region.

The amplification of the ITS region was successful for both P. pulmonarius and isolate S15. The bands produced were within the range of 450 to $550 \mathrm{bp}$. Due to the smearing of the ladder and the amplicons, it was difficult to accurately determine the size of the amplicons. This could have been avoided by extending the period of the gel electrophoresis and running it at a lower voltage. The smearing at the bottom of the gel, known as primer dimers, could also be avoided by reducing the total concentration of the primers used. 
Table 3. Microscopic characterisation of isolate S15, P. pulmonarius, and T. asperellum.

Sample Isolate $\mathrm{S} 15 \quad \begin{gathered}\text { T. asperellum (soft) } \\ \text { (Podder \& Ghosh, 2019). }\end{gathered}$

- Hyphae of the isolate were

\section{Observations}

present

- Numerous conidia were spotted around the hyphae

- Several branching conidiophores with phialides were observed
- No fruiting bodies were observed

- Several clamp connections were present

- The hyphae were visible
- Conidia were present in the background

- Conidiophores were observed

- The hyphae were visible 


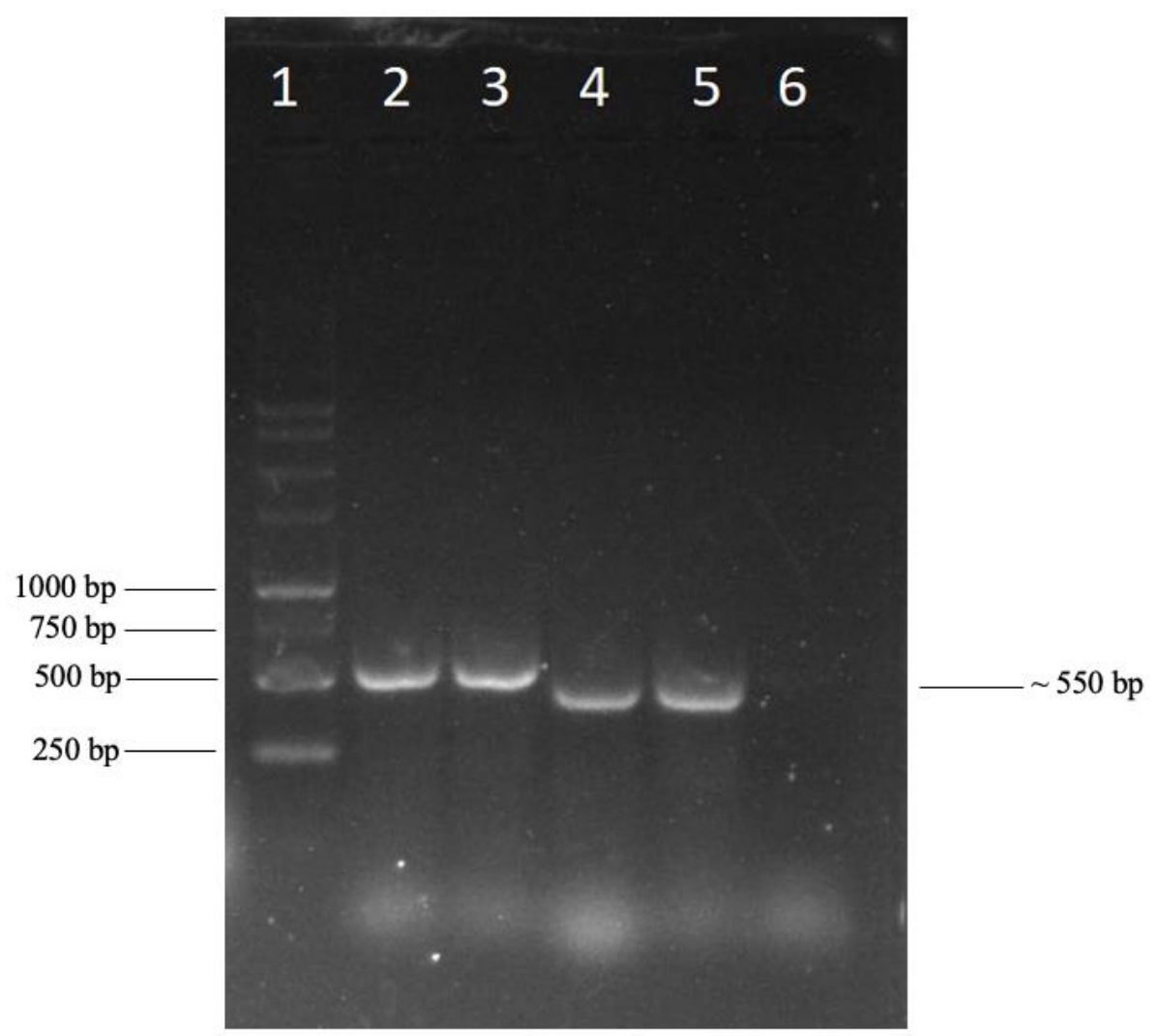

Figure 2. Agarose gel electrophoresis analysis of amplified ITS region.

Lane 1: $1 \mathrm{~kb}$ DNA ladder. Lane 2-3: Isolate S15. Lane 4-5: P. pulmonarius. Lane 6: Negative control

\section{Sequencing and identification of the amplified region}

The ITS region is known as the most widely sequenced DNA region for fungi and is known to be the universal fungal barcode sequence (Peay et al., 2008; Schoch et al., 2012). Since the region contains both conserved and variable regions, it is not unusual to get different sizes of bands when amplifying different species.

Based on the results, the PCR products for the isolate S15 was sent for sequencing to MyTACG Biosciences, Malaysia. The resulting sequence was then aligned through BLAST.

From the results, it was found that the amplified ITS region of isolate S15 was $94.27 \%$ identical to Trichoderma asperellum, with a total score of 520 and query cover of $94 \%$. It was also 92.19\% identical to T. asperellum strain CTCCSJA-SD3908, with a total score of 755 and query cover of $94 \%$. The band size obtained was also similar to the one obtained by Podder and Ghosh (2019) when they amplified T. asperellum using primers ITS1 and ITS4 as they also obtained a band size of approximately over $500 \mathrm{bp}$. The morphological characteristics of the isolate also match the description of T. asperellum (Wu et al., 2017; Podder and Ghosh, 2019). Hence, it is believed that isolate $\mathrm{S} 15$ is $T$. asperellum. The sequence was deposited into GenBank with the accession number MW228039 and MW228044.

There are a number of studies utilising $T$. asperellum in the treatment of dye, such as the one conducted by Shanmugam et al. (2017), and Marcharchand and Ting (2017). In the study by Marcharchand and Ting (2017), T. asperellum was shown to be able to decolourise four types of triphenylmethane dyes in reduced concentrations of PDB without affecting its efficacy. Furthermore, in the study by Shanmugam and his colleagues (2017), laccase from T. asperellum was utilised in the degradation of crystal violet, whereby a maximum degradation of $97.05 \%$ was achieved. These studies showed that isolate S15, T. asperellum, is also a promising candidate for decolourisation studies of dyes.

\section{CONCLUSION}

To conclude, in this study, out of 20 fungal isolates, only one isolate was found to be capable of producing ligninolytic enzymes. The isolate was identified using ITS region sequencing and 
was identified as T. asperellum, a type of soft rot fungi. Further investigations should be done on the activity of this isolate to treat dyes.

\section{REFERENCES}

Adegoke, K. A., \& Bello, O. S. 2015. Dye sequestration using agricultural wastes as adsorbents. Water Resources and Industry 12: 8-24.

Agudelo-Escobar, L.M., Gutiérrez-López, Y., Urrego-Restrepo, S., Agudelo-Escobar, L. M., Gutiérrez-López, Y., \& UrregoRestrepo, S. 2017. Effects of aeration, agitation and $\mathrm{pH}$ on the production of mycelial biomass and exopolysaccharide from the filamentous fungus Ganoderma lucidum. DYNA 84: 72-79.

Ali, H., Ahmad, W., \& Haq, T. 2009. Decolorization and degradation of malachite green by Aspergillus flavus and Alternaria solani. African Journal of Biotechnology 8(8).

Ansari, M. A., \& Butt, T. M. 2011. Effects of successive subculturing on stability, virulence, conidial yield, germination and shelf-life of entomopathogenic fungi. Journal of Applied Microbiology 110(6): 1460-1469.

Chi, Myoung-Hwan, Park, Sook-Young, \& Lee, Yong-Hwan. 2009. A quick and safe method for fungal DNA extraction. The Plant Pathology Journal 25(1): 108-111.

Couto, S. R. 2009. Dye removal by immobilised fungi. Biotechnology Advances 27(3): 227-235.

da Silva, B. P., Corrêa, R. C. G., Kato, C. G., de Souza, D. F., Bracht, A., \& Peralta, R. M. 2016. Characterization of a solvent-tolerant manganese peroxidase from Pleurotus pulmonarius and its application in dye decolorization. Current Biotechnology 5(2).

Doble, M., \& Kumar, A. 2005. CHAPTER 11-Textile Effluent. In: M. Doble \& A. Kumar (Eds.), Biotreatment of Industrial Effluents. pp. 123-132. Butterworth-Heinemann.

dos Santos, A. B., Cervantes, F. J., \& van Lier, J. B. 2007. Review paper on current technologies for decolourisation of textile wastewaters: Perspectives for anaerobic biotechnology. Bioresource Technology 98(12): 2369-2385.

dos Santos Bazanella, G. C., de Souza, D. F., Castoldi, R., Oliveira, R. F., Bracht, A., \& Peralta, R. M. 2013. Production of laccase and manganese peroxidase by Pleurotus pulmonarius in solid-state cultures and application in dye decolorization. Folia Microbiologica 58(6): 641-647.

Johannes, C., \& Majcherczyk, A. 2000. Laccase activity tests and laccase inhibitors. Journal of Biotechnology 78(2): 193-199.

Kant, R. 2012. Textile dyeing industry an environmental hazard. Natural Science 4: 22-26.

Katheresan, V., Kansedo, J., \& Lau, S. Y. 2018. Efficiency of various recent wastewater dye removal methods: A review. Journal of Environmental Chemical Engineering 6(4): 4676-4697.

Lallawmsanga, Leo, V. V., Passari, A. K., Muniraj, I. K., Uthandi, S., Hashem, A., Abd_Allah, E. F., Alqarawi, A. A., \& Singh, B. P. 2019. Elevated levels of laccase synthesis by Pleurotus pulmonarius BPSM10 and its potential as a dye decolorizing agent. Saudi Journal of Biological Sciences 26(3): 464-468.

Leonowicz, A., Matuszewska, A., Luterek, J., Ziegenhagen, D., Woitaś-Wasilewska, M., Cho, N.-S., Hofrichter, M., \& Rogalski, J. 1999. Biodegradation of Lignin by White Rot Fungi. Fungal Genetics and Biology 27(2): 175-185.

Marcharchand, S., \& Ting, A. S. Y. 2017. Trichoderma asperellum cultured in reduced concentrations of synthetic medium retained dye decolourization efficacy. Journal of Environmental Management 203: 542-549.

Mir-Tutusaus, J. A., Baccar, R., Caminal, G., \& Sarrà, M. 2018. Can white-rot fungi be a real wastewater treatment alternative for organic micropollutants removal? A review. Water Research 138: 137-151.

Niku-Paavola, M.-L., Karhunen, E., Kantelinen, A., Viikari, L., Lundell, T., \& Hatakka, A. 1990. The effect of culture conditions on the production of lignin modifying enzymes by the white-rot fungus Phlebia radiata. Journal of Biotechnology 13(2): 211-221.

Paul, J. S., Tiwari, K. L., \& Jadhav, S. K. 2015. Long Term Preservation of Commercial Important Fungi in Glycerol at $4^{\circ} \mathrm{C}$. International Journal of Biological Chemistry 9(2): 79-85.

Pearce, C. I., Lloyd, J. R., \& Guthrie, J. T. 2003. The removal of colour from textile wastewater using whole bacterial cells: A review. Dyes and Pigments 58(3): 179-196.

Peay, K. G., Kennedy, P. G., \& Bruns, T. D. 2008. Fungal Community Ecology: A Hybrid Beast with a Molecular Master. BioScience 58(9): 799-810.

Pink, D. H. 2006. Investing in Tomorrow's Liquid Gold: The Trend Desk - Yahoo! Finance. YAHOO! Finance. https:// finance.yahoo.com/columnist/article/trenddesk/ 3748

Podder, D., \& Ghosh, S. K. 2019. A new application of Trichoderma asperellum as an anopheline larvicide for eco friendly management in medical science. Scientific Reports 9(1): 1108.

Pointing, S. B. 1999. Qualitative methods for the determination of lignocellulolytic enzyme production by tropical fungi. Fungal Diversity 2: 17-33.

Safavi, S. 2011. Successive subculturing alters spore-bound Pr1 activity, germination and virulence of the entomopathogenic fungus, Beawveria bassiana. Biocontrol Science and Technology 21: 883-891.

Schoch, C. L., Seifert, K. A., Huhndorf, S., Robert, V., Spouge, J. L., Levesque, C. A., Chen, W., \& Consortium, F. B. 2012. Nuclear ribosomal internal transcribed spacer (ITS) region as a universal DNA barcode marker for Fungi. Proceedings of the National Academy of Sciences 109(16): 6241-6246.

Shanmugam, S., Ulaganathan, P., Sivasubramanian, S., Esakkimuthu, S., Krishnaswamy, S., \& Subramaniam, S. (2017). Trichoderma asperellum laccase mediated crystal violet degradation-Optimization of experimental conditions and characterization. Journal of Environmental Chemical Engineering 5(1): 222-231.

Tang, Y.-J., Zhu, L.-W., Li, H.-M., \& Li, D.-S. 2006. Submerged Culture of Mushrooms in Bioreactors- Challenges, Current State-of-the-Art, and Future Prospects. Food Technology and Biotechnology 45.

Tychanowicz, G. K., Zilly, A., de Souza, C. G. M., \& Peralta, R. M. 2004. Decolourisation of industrial dyes by solid-state cultures of Pleurotus pulmonarius. Process Biochemistry 39(7): 855-859.

Wesenberg, D., Kyriakides, I., \& Agathos, S. N. 2003. White-rot fungi and their enzymes for the treatment of industrial dye effluents. Biotechnology Advances 22(1): 161-187.

Wood, D. A. 1980. Inactivation Of Extracellular Laccase During Fruiting Of Agaricus Bisporus. Journal Of General Microbiology 117: 339-345.

Wu, Q., Sun, R., Ni, M., Yu, J., Li, Y., Yu, C., Dou, K., Ren, J., \& Chen, J. 2017. Identification of a novel fungus, Trichoderma asperellum GDFS1009, and comprehensive evaluation of its biocontrol efficacy. PLoS ONE 12(6).

Yuan, H.-S., Dai, Y.-C., \& Steffen, K. 2012. Screening and evaluation of white rot fungi to decolourise synthetic dyes, with particular reference to Antrodiella albocinnamomea. Mycology 3(2): 100-108. 